\title{
1732-1791, la Ilustración y la crisis del modelo defensivo español en el Norte de Africa
}

Fernando R. de la Flor

Universidad de Salamanca

Podrá hacer esto un Príncipe muy bien, con tener mucho cuidado de que estén bien fortalecidas las plazas principales de su estado, con muy buenos fuertes en las fronteras $y$ pasos por donde puede entrar el enemigo, reguladas de manera que el que las hubiere de defender tenga satisfacción de ellas.

Gonzalez de Medina Barba, Examen de fortificación, 1599.

\section{BL PEOBLRMA Y 8 US MARGBNES}

Un subepígrafe introducido por los organizadores de este Congreso llama poderosamente la atención por su formulación, que es algo así, creo recordar, como :"Los gobiernos ilustrados y la situación del Norte de Africa".

Los redactores de la convocatoria suponían entonces que había habido una política "ilustrada" que se había comportado de una manera específica con el Norte de Africa (Carcedo, 1839; Rodríguez Casado, 1946). Esto me abría una interesante perspectiva que es la que aquí deseo explorar: no me cuestiono ya respecto a la cuestión africana la actuación de los gobiernos ilustrados en global (y gobiernos ilustrados pese a lo que pueda parecer ha habido algunos en nuestro país ), sino del "gobierno ilustrado" por antonomasia; es decir, por el período de Carlos Tercero que había comenzado en 1759 y concluido, en medio de muchas sombras, en 1788. 
De modo que de una manera al principio intuitiva me pareció que singularmente en ese periodo se habrían debido fraguar importantes decisiones que afectaban a todas las plazas y presidios, que un poco como herencia de otros días conservaba la Corona española en esas fechas.

Sin embargo, y para ser enteramente fiel al presupuesto de la cronología misma con que la Ilustración se producía en nuestro país, se hacía preciso tener en cuenta, como efectivamente lo he hecho, un periodo más laso de tiempo: por un lado, amplié, pues, las fechas hasta la década de los años treinta, que eran los tiempos en que un conocido ministro de Felipe V, José Patiño, inicia una interesante serie de reformas en la organización administrativa y militar del territorio de la Corona. Además, por aquellos años también se había producido la reconquista de Orán, episodio trascendental, según lo vamos a considerar más adelante. Por otro lado, el de esta vertiente, convenía cerrar la fecha de la exploración haciéndola coincidir, no sólo con el final efectivo del movimiento ilustrado y reformista, sino, también, con algún otro acontecimiento de importancia que hubiera modificado drásticamente la situación por la que atravesaba la presencia española en Africa. Una fecha armoniza y sintetiza estos dos momentos: es, como pueden suponerse, la de 1791, año singularmente nefasto para la causa del progreso en nuestro país y año también, en definitiva, donde se producía la definitiva pérdida final de Orán, que dejaría en precario, al menos desde un punto de vista geoestratégico, todo el tejido defensivo construido a lo largo de tanto tiempo y de tantos esfuerzos.

Una vez tomada así la decisión sobre la cronología histórica de la que deseaba hablar, quedaba todavía fijar en concreto cual habría de ser el objeto mismo de esa pesquisa, objeto que no podía ser otro, dado el ámbito restringido de mi especialización, que la poliorcética, es decir, aquel conjunto de decisiones que afectan a la existencia de un "espacio militar", a la también llamada logística, y en fin, considerándolo "in extenso", al complejo de relaciones que unen a un Estado con su "máquina de guerra" (Virilio, 1991, págs. 22 y ss.), sobre todo en lo que ésta tiene de fortificación, de defensa.

Y me gustaría con ello adelantar aquí una visión general de este asunto, que desde luego no trataré con detenimiento, pero que incide en la configuración de todo lo que es y ha sido la presencia española en el Norte de Africa: esa máquina de guerra, es una máquina de guerra inmóvil, 
inmovilizada, y por tanto desde el momento de su configuración arquitectónica primera se encuentra condenada a un continuo proceso de erosión y de reconstrucción, que en la práctica no ha cesado nunca. Como lo expresaba poéticamente en el siglo XVIII González de Torres:

Viniendo de Orán a partir de la puerta de Mallorca hacia poniente, a una legua entre el castillo de San Gregorio y la ermita de Nuestra Señora del Carmen, se puede ver la bahía o gran puerto de Mazalquivir, muy capaz para muchos navios y protegido por un incomparable castillo, que se alza directamente de las rocas, imperturbable como éstas a los golpes repetidos de las olas, siempre combatiente y siempre glorioso, en vano golpeado por el flujo y reflujo de las aguas.

O, como tal vez se veía también, desde un punto de vista simbólico: es decir, si España era toda ella una plaza fuerte, una (o "la", por antonomasia) ciudadela cristiana a que aspiraba desde los tiempos de la constitución del Imperio Austria; el mar Mediterráneo configuraba entonces una suerte de foso natural que la separaba de sus enemigos, mientras que los presidios y plazas exteriores cumplían el papel de ser antemurallas en la salvaguarda de la Corona. Precisamente en función de ser barreras avanzadas "adelantadas", tienen inscrita en su misma ubicación su destino y régimen; es decir, su conflictividad permanente que determina una articulación estrictamente militar, polemológica.

Una circunstancia feliz para mí venía a coincidir para darle relevancia e interés a esta pequeña sintésis de la exploración que les ofrezco: estando realizando en estos momentos una edición del Tratado de fortificación del que era primer director de la Academía de Matemáticas de Barcelona, donde se formaron los ingenieros militares que luego actuarían en Orán, en Ceuta, en Melilla, la problemática que en aquellos momentos presentaba el sistema que se pretendía para la defensa africana me era relativamente conocido y, además, en esos años que me he fijado, se abría y se cerraba también un proceso por el que me encuentro singularmente interesado y del que habré luego de dar cuenta: el de la constitución de academias de matemáticas para la formación de ingenieros en el Norte de Africa (R. De La Flor, 1991). Me referiré entonces a su debido tiempo y con cierta 
amplitud a esa acción ilustrada que fue la creación de estos establecimientos en Ceuta y en Orán.

En todo caso, mi revisión de las relaciones en el plano en que las he situado brevemente para ustedes, no podría realizarse sino a través de los documentos generados particularmente desde esas intancias de poder, a las que vamos a definir como "ilustradas". La pregunta era en concreto ¿qué textos, qué documentos habrían producido esas mismas instancias y, paralelamente, qué novedades o a qué reconsideraciones nuevas habrían conducido al antiguo y espinoso tema de la integración militar en un proyecto de defensa común del Norte de Africa y de la Península (García Figueras, 1962).

Tengo que decir, porque eso interesa hoy aquí -interesa, por supuesto, el saber dónde están los documentos fantásticamente dispersos que afectan a esta ciudad o "in extenso" a todas las antiguas o supervivientes plazas de dominio español一, que estos documentos que voy a utilizar proceden de diversos orígenes, el más importante y original de ellos proviene en concreto de la Biblioteca del Escorial, donde está depositado un fondo sin clasificar denominado como Papeles de Orán.

\section{LA DIFICTL AFCONBTRUCCION DEL MODELO DF DEFENSA}

Es este documento - una relación de obras de fortificación redactada por el gobernador de Orán José Vallejo- con el que desearía comenzar, el que nos sitúa en la fecha de 1738. Un momento singular este en la historia de España, por cuanto terminadas en él la primera fase de las guerras exteriores mantenidas por la Corona; concluida ya también desde hace tiempo la Guerra de Sucesión; asentada la monarquía de Felipe V, sus gabinetes de ministros se enfrentan ya a una reforma cualitativa de la administración y de la logística del Estado en todos sus órdenes: el sanitario, el administrativo, el universitario, finalmente también el propiamente militar.

En lo que a la organización defensiva de la Corona se refiere, la década de 1730 supone la puesta en marcha de un plan periférico de la defensa estatal, que había tenido ya sus tímidos comienzos reorganizativos en el año 1717 con la elaboración de un Reglamento para el gobierno de las plazas norteafricanas.

Se recupera en aquel entonces a impulsos de pensamientos ilustrados y renovadores, la imagen de un país por fin custodiado y preser- 
vado frente a la amenza extranjera. Las plazas fuertes, los puertos de importancia, las fronteras mismas son para el pensamiento de la época la corona defensiva de este país que se desea fortalecido frente a toda amenaza extranjera. Las fronteras son también el caparazón mismo, la concha o el erizo (todas ellas metáforas del orden militar), de un país que desea reconstruirse en lo interior mientras aleja el peligro exterior. Como se lee en los Diálogos del arte militar:

Los confines de un reino tienen alguna correspondencia con el circuito de una ciudad, en la fortificación de la cual los baluartes son los más importantes miembros que hay, los cuales se ponen en la parte que pueden ofender más al enemigo y defenderse a sí mismos y a la ciudad, guardándose la debida distancia de suerte que el uno defienda al otro con la artillería y arcabucería... Y asi las fortalezas que se hacen en los confines deben de tener la misma correspondencia con el reino como los baluartes con una ciudad, haciéndose tan vecinas que la una pueda socorrer a la otra.

Cádiz, Cartagena, La Coruña, San Sebastián, la Frontera portuguesa (R. de la Flor, 1987), Figueras, las costas levantinas..., reciben precisamente en aquella década una primera oleada de ingenieros militares empleados en la reconstrucción de un sistema de defensa en buena medida periclitado, envejecido, descuidado, por lo menos desde mediados del siglo XVII.

Todo el contorno peninsular recibe esta acción del Estado que se manifiesta en el trabajo de un nuevo cuerpo de servidores tecnológicos que son los ingenieros militares, empeñados por aquel entonces en poner el país en lo que se llama "orden de defensa".

Estos ingenieros se caracterizan, además, por tener una visión general de la problemática de la defensa, que ya no es más como hasta entonces se pensaba un asunto exclusivo del Ejército, sino que tiene que ver con la organización integral de un territorio "sub especie militari", es decir, con una imagen compacta del Estado y de sus mecanismos; imagen que hay que proyectar hacia el exterior si se quiere ser respetado y temido.

Es en orden a completar esta imagen, a dotar al Estado de todos sus órganos y factualidades, que vemos comenzar en aquella década 
precisamente una reconsideración integral de la cuestión africana, particularmente en su versión poliorcética, es decir, se siente la necesidad primordial de readaptar el sistema de fortificación de ultramar como primer paso -y no "ultima ratio"- de una nueva política civil (Epalza, 1979). Como escribía el ingeniero militar Antonio Gaver que paso muchos años en las plazas del Norte de Africa y que fue incluso director de la Academia para ingenieros de Orán:

En todas partes las fortificaziones acuerdan la autoridad del Soberano, sujetan los pueblos a la Soziedad y obediencia, maiormente a los que habitan distante de las plazas fortificadas; cuio olbido les impide la frecuenzia con la tropa ; y en cualquier caso havisan la bigilancia (R. de la Flor, 1987, pág. 145).

Es la necesidad urgentemente sentida de completar la estructura de un estado poderoso y de afirmar simbólicamente su presencia en el área que ocupa, por lo que se emprende por aquel entonces (1732) la reconquista de Orán. Este será el primer esfuerzo, el primer paso de la llustración española para cerrar, al menos en la fachada africana, la órbita de su actuar.

La toma de Orán, como se llamó, es una de las conquistas militares más largamente loadas y cantadas en textos como los del Encomiasticon o verdadera descripción y el elogio de la expedición de Africa en que las Reales Armas de su magestad recobraron a Mazalquivir, Orán y sus castillos, (Granada, s.a.) por De Cueva, o en la memoria fúnebre de los soldados que murieron en la célebre conquista de la plaza de Orán y sus castillos... (Segovia,1732), de Sarmentero. ... Conquista que haya más su justificación, si se quiere en el plano de lo simbólico, de lo psicológico, y que como tal está destinada a crear una imagen interior y exterior de un Estado poderoso y coherente con su tradición guerrera y conquistadora.

Este paso inaugural y decisivo para nosotros con respecto a la política que la Ilustración sigue en Africa es, al mismo tiempo, el último de los avances realizados por nuestro país en ese territorio.

Ese gesto de conquista sobrevalorado, funda, así, al mismo tiempo, el inicio de una crisis profunda de todo el modelo defensivo. El día 
después de la conquista, los militares ilustrados y los hombres de gobierno se verán obligados a hacer frente a esta herencia sembrada de dificultades. Por fidelidad a su país; por fidelidad a una imagen ya imposible de una nación hegemónica, estos ilustrados van a verter en sus documentos todas las amargas y paradójicas reflexiones que la situación les procura.

En concreto, por lo que nos interesa a nosotros hoy aquí, en Orán, pero también en Ceuta y por supuesto en Melilla, a la que aludiremos más adelante, estos militares, en numerosas ocasiones ingenieros, van a poner en marcha brillantes e imaginativas soluciones que afectan sobre todo al espacio militar en su versión poliorcética, van a reconstruir con sabiduria, eficacia - y hasta con "belleza" - estos conjuntos poliorcéticos de las plazas españolas en el Norte de Africa (Epalza y Vilar,1988), y lo van a hacer como siempre se han hecho estas cosas en nuestro país, en medio de una carencia de medios, en el seno de turbulencias políticas, y flanqueados por derrotas militares y pérdidas territoriales, generalizadas a todo lo largo de lo que había sido el antiguo imperio español.

Este tiempo de reconstrucción que enseguida vamos a examinar, lo es también en lo que atañe a la organización misma del territorio. Las memorias que he consultado, las de La Mina, Vallejo, etc., atienden no sólo a planificar el fortalecimiento de la estructura arquitectónica de los presidios y plazas de soberanía, sino a reorganizar también bajo presupuestos ilustrados todo lo que es su vida económica, mercantil, civil, etc.

El orden militar, su sentido de lo que es un espacio, toma bajo su control la estructura entera de estos lugares estratégicos y los modela de una manera tan ejemplar que logra mantenerlos bajo su dominio por largos espacios de tiempo, por encima incluso de todo tipo de circunstancias y dificultades.

El primero de esos documentos básicos para la historia de esas relaciones entre el estado ilustrado y la presencia española en el Norte de Africa, es un texto que pertenece a José de Vallejo, el cual había sucedido en el gobierno de Orán a quien había sido un ilustre militar de la Ilustración, el marqués de Santa Cruz del Marcenado. EI documento en cuestión es una Relación de todas las obras de Fortificación y correspondientes a ella, que se han executado en las Plazas de Orán, Mazarquivir y sus castillos.

Empezemos por señalar la importancia que para Orán tuvo el período del gobierno de José Vallejo qụe, durando escasamente dos años 
(del 1736 a 1738 ), cambió por entero la organización civil y militar de la ciudad en un sentido ilustrado de potenciación de la red viaria, de la infraestructura sanitaria, de los edificios e hitos representativos (M. de Epalza, págs. 91 y ss).

No me voy a detener en la memoria de Vallejo plagada por lo demás de referencias a la arquitectura militar de la plaza, que por entonces se renueva sistemáticamente en su concepción defensiva, modificando su estructura y elementos, lo que, en ocasiones, como el mismo Vallejo escribe, viene a suponer lo que son "las primeras intervenciones desde el tiempo de los romanos" (Vallejo, 1738, pág. 2), pero no puede dejar de pasar desapercibida la ingente modernización a la que el gobernador sometió a la plaza y que pasaba por una articulación y funcionamiento en profundidad, vaubaniano diríamos, de las defensas; construcción por lo tanto de recintos y circuitos exteriores (al menos hasta dos se llegaron a construir exteriores al perímetro de las antiguas murallas), con una red de comunicaciones, en buena medida subterráneas, que hicieron famosa por aquel entonces a Orán (Epalza y Vilar, 1984).

La higiene y la belleza de las proporciones son consideraciones que nunca faltan en el tratamiento de gestión militar de la plaza, y hay también en la misma insistencia con que se manifiesta la problemática de las proporciones un ideal neoclásico activo, que trata de enlazar y prestar coherencia a todo el sistema de fortificación, en alguna parte, como he dicho, heredado de los romanos.

El regimiento interno de la plaza ocupa también las páginas de la Relación que no dejan de indicar incluso los detalles más pequeños, como la presencia de un reloj de campana que, traído de Londres, rige y compartimenta y redistribuye la producción de un tiempo militar y que constituye, si quieren, una especie de metáfora del nuevo orden y la nueva mentalidad. Junto a todo ello, Vallejo describe el trabajo diplomático realizado en esos años en orden a restituir la plaza al destino geográfico y humano de la que la política exterior la ha abstraido.

Vallejo es el primer gobernador militar de los tiempos modernos por cuanto emplea su potencial guerrero en crear estrategias de paz en la zona; en estimular a una población indígena de paz para que se asiente en la plaza, creando así un germen de vida civil siempre al borde de la extinción en el sistema de los presidios españoles (Dechaud, 1908). 
Toda la geoestrategia ensayada por Vallejo va también encaminada a suprimir esa peligrosa noción del hinterland, de la tierra vacía o quemada o de nadie, que con frecuencia viene a ser el corolario de la ocupación por la fuerza de un pequeño punto en un vasto territorio o en país ajeno. Para ello improvisó sistemas de intercambio y de comercio; extendió la protección y el dominio visual de la plaza sobre el territorio cercano, creando una red de vigilancia y de presencia militar que, sin embargo, era conciliable con la expansión comercial, con el intercambio y con la llegada de nuevas poblaciones agregadas.

En este orden de cosas diría, y esto no ha sido realmente señalado, que yo sepa, que Vallejo es también el ideólogo que anima la creación de un tipo de contingente militar que en el futuro sería adoptado en casi todos los ejércitos del mundo. Hay en su Relación - y me detengo en ello aún cuando el asunto es tangecial enteramente a mi interés de este momento- una referencia a la formación - primera referencia que yo conozca, insisto- de una tropa o compañía indígena, árabe, constituida con sus propias armas e integrada en el sistema del ejército incluso a un nivel jurídico, y que viene a reforzar el dispositivo militar siempre necesitado de personas. Esta compañía de "mogatazes" (Vallejo, 1738, pág. 39), que así se llaman, creada dentro del ejército español en el año 1734, como señala Vallejo, debería ser estudiada dentro de la historia militar de los tiempos modernos como un antecedente preciso de los gurkas, de lo que luego fueron los tabores de regulares y, en fin, de toda tropa índigena que sirve en el propio territorio a los fines de un ejército extranjero.

La referencia, que plantea una serie de problemas en la constitución de esta fuerza indígena es textualmente la siguiente:

Aunque se formó esta compañía por el mes de Julio del año pasado de 734 y debía constar de cien Moros montados, con su capitán, Theniente y dos sargentos, hasta aora no se han podido reclutar, ni aun 24 cavales por la aversión que tienen estos Bárbaros a servir con este nombre; $y$ en esta clase; y tampoco se han podido comprar mas de igual número de cavallos para ellos, sin embargo de las diligenzias practicadas para su logro, por lo difizil que es quieran vender, no sólo los buenos, pero ni aun los razonables; a causa de que como todos 
los Arabes viven contínuamente a cavallo, y están entre si en perenne guerra, quieren hallarse bien montados, y para lograrlo los pagan a excesivos precios (Vallejo, 1738, pág. 40).

Las novedades digamos "ilustradas" introducidas en Orán por Vallejo en orden a su modernización y normalización, son innumerables y, como he dicho, no afectan exclusivamente a la constitución de un orden militar, sino que suponen más bien la modelización que el orden militar impone a un mundo civil, al que por primera vez de un modo progresista ampara, protege y trata de desarrollar.

No es extraño ese intervencionismo de la esfera militar en el desarrollo de lo civil, estas fórmulas de interrelación proliferaron durante todo el siglo XVIll, lo que constituye una de las características peculiares de la época; sobre todo cuando una serie de militares formados en las academias militares advienen al gobierno de las plazas peninsulares o extraterritoriales.

Una formación más rica y completa de la élite militar y una asunción del papel dinamizador en la sociedad que les compete, compone ahora el nuevo cuadro en donde una concepción logística; donde una nueva gestión de lo territorial, se está fraguando. Vallejo, en este orden de cosas, fue, incluso, el introductor en la plaza de Orán de un sofisticado sistema de pago, mediante aval o letra, que sirvió para las relaciones entre las dos comunidades - la autóctona y la foránea-, y eso en unos años en los que la corriente monetaria correspondiente a los̀ sueldos de los españoles al servicio de la Corona no llegaba ni con regularidad, ni con abundancia.

Es el propio Vallejo el que en su Relación realiza la observación sorprendida de que ese sistema de aval, corriente entonces en la plaza, no podría funcionar en las metrópolis de la Península, y el hecho de que funcionara en Orán no era sino una prueba de la confianza que los mecanismos del Estado suscitaban, no sólo entre sus súbditos naturales, sino también en todos aquellos que habían sido conquistados por la fuerza. Y no conviene olvidar a este respecto que Orán era entonces una plaza recién reconquistada, una plaza fuerte en el "limes", en la frontera más peligrosa y más removida quizá por aquel entonces de todo el reino.

Pero para terminar de agotar la lectura del informe de Vallejo, que desde mi punto de vista tan cumplidamente da cuenta de un cambio sustancial en el sistema de relaciones operadas en el Norte de Africa, desde 
el momento mismo en que advienen al gobierno y a las instituciones estatales una nueva generación de hombres próximos al espíritu de la Ilustración, habría que mencionar también la sensibilidad con que Vallejo contempla la nueva función del ejército y la actividad constructiva militar, que ya no se encuentra encasillado en una posición, digamos "numantina", sino que se torna dialogante y que, en términos de otro ingeniero militar ilustrado de la época, tiende a "amparar cuanto defiende".

La protección a las tribus y a los "moros de paz", a aquellos de los que se llega a decir jen un informe militar! que tenían "su corazón en esta plaza" (Vallejo, 1738, pág. 44) fue una obsesión de Vallejo y el deseo de extender hacia el glacis defensivo, es decir, hacia el más allá del territorio, la obra de fortificación, no es sino el reflejo, si se quiere simbólico, de esa necesidad de integrar lo mismo un nuevo espacio que, sobre todo, operara esa reabsorción sobre el conjunto de personas que viven en él bajo la calidad de súbditos.

En este orden de cosas, no puedo dejar de señalar tampoco la preocupación de Vallejo por, digamos, recuperar esa población autóctona, en este caso a los oraneses de siempre, que durante estos primeros treinta años del siglo XVIII habían tenido que soportar hasta tres administraciones diferentes y dos guerras o asedios. ¿No es acaso esta preocupación por la repoblación, por la seguridad de la vida civil, paralela u homóloga a aquella otra sensibilidad que demostraría Olavide en Sierra Morena, Goyeneche en Nuevo Batzán o el propio Carlos III, promoviendo la fundación de ciudades ideales, poblamientos casi utópicos del tipo de La Carolina? (Merino, 1988).

Para finalizar, y este es un asunto de suma importancia desde el punto de vista de lo que hoy tratamos, Vallejo hace un apuntamiento acerca de una institución sobre cuya esencia "ilustrada", innovadora, pocas dudas cabe hoy tener. Vallejo reseña en su manuscrito (Vallejo, 1738, pág. 47) la existencia de una Academia de Mathemáticas para la formación de arquitectos ingenieros militares en Orán. (Reglamento 1735, págs. 91-113.)

En esta Plaza se ha extablecido con aprovazion de S. M. una Academia de Mathematicas para instrucción de los Ofiziales y Cadetes que se inclinaxen a su estudio, las que explica el Ingeniero Ordinario Don Antonio Gaber, con buen Mhetodo, y claridad, y actualmente tiene 45 discipulos de 
ambas clases, entre los quales se distinguen algunos ya en la inteligencia con que van aprehendiendo, $y$ en todos ay aplicación a lo mismo (Vallejo, 1738 pág. 48).

Basta un dato para restablecer en su total importancia la existencia misma de este centro pedagógico: en esos momentos sólo había una otra academia dentro del territorio peninsular - la de Barcelona- más otra situada en Ceuta,viniendo a ser denominadas las norteafricanas como "particulares", frente a la "Real y General" aplicada a Barcelona.

La existencia misma de estos centros activos, denuncia por parte de sus promotores la importancia que para ellos alcanza la presencia española en Africa, y el rigor y el cientificismo, podríamos decir, con que se aprestan a defender esa presencia, explotando todas las posibilidades a su alcance. Sin embargo, la fundación de la Academia no es enteramente achacable en este caso a Vallejo, sino que debemos ver en esta fundación el cumplimiento de la aspiración activa del ingeniero militar Jorge Próspero de Verboom, encargado por Felipe $V$ de la reorganización total del sistema de enseñanza en el Ejército y de la creación de un Cuerpo de ingenieros especializado, del que fue su primer Director general (Gómez de Arteche, 1899 , págs. 343-350).

Verboom estuvo en Orán y de su visita surgiría sin duda la idea de dotar a todo el Norte de Africa de nuevos viveros para la formación científica de una clase de militares expertos, sí, pero hasta entonces sin formación específica.

\section{LOS PLANTBAMIENTOS GPOE8TRATEGICOS DE IA ILUSTRAGION}

Vemos pues cómo se desarrolla ante nuestros ojos, en un corto periplo de tiempo, toda una serie de intervenciones variadas, identificables con las aspiraciones generales del movimiento ilustrado y que de todos modos se encuentran también contrapesadas por la aparición de un pensamiento crítico, que reconoce como ya llegado el tiempo de las revisiones de las estrategias geopolíticas.

Los mismos hombres —como es el caso de Vallejo, y, después el de Arámburu y O'Reilly (El Korso y Epalza, 1978) - que ponen en pie un sistema de reformas necesarias, no dejan al mismo tiempo de ejercer su crítica implacable en el caso de esa herencia del pasado que entonces era 
Orán, y que en cierto modo lo eran también los presidios situados en las costas frente a la España peninsular.

Digamos enseguida que todo el entusiasmo y energía que trasmite el informe denominado Relación de las obras de fortificación que se han executado en... Orán..., se convierte en convicciones pesimistas sobre el futuro de la plaza en otra memoria, esta sí conocida, que redactó también Vallejo. Se trata de su Memoria sobre el estado y valor de las plazas de Orán y Mazalquivir (Vallejo, 1925 ).

Producto de una mentalidad reformista, la amplia memoria es el primero de los análisis fríos que vemos realizar en la España del XVIII. Las ventajas y desventajas del mantenimiento bajo la Corona de la plaza de Orán se sopesan, desde la perspectiva de una prioritaria dimensión económica y de la sangría militar que supone su mantenimiento. El memorial elevado como respuesta a una consulta, resulta ser el primer documento claramente inclinado al abandono de las posesiones, y hay que decir a este respecto que fue también el primero de los informes que en este sentido fueron rechazados en lo que constituía su propuesta por la Secretaría de la Guerra, cuya visión de la importancia de los establecimientos dependía entonces casi exclusivamente de la virtualidad que éstos tenían de disuadir al corso argelino, éste ya por esos años en franca decadencia (Epalza, 1988 pág. 70).

Pero si nos trasladamos de Orán a lo que constituye el centro mismo de los debates de esta reunión, si nos trasladamos a las llamadas Plazas de soberanía y Presidios menores, si nos preguntamos por la suerte de Melilla, de Alhucemas, de Peñón, lo que de ellos fue durante los años de los gobiernos ilustrados de Patiño, de Ensenada, de Floridablanca, tendremos que adelantar la idea en lo que a estos territorios se refiere, que para ellos también hubo un tiempo de reconstrucción y de reordenamiento de ese espacio militar completamente liminar -las llamadas "adelantadas de España" (Arqués, 1966) - que tan bien y tan ejemplarmente encarnan los pequeños territorios aludidos.

Durante la llustración, la posición de estos territorios; la especial perspectiva de la organización militar de sus condiciones de defensa, fue pasada por el tamiz de la crítica, fue analizada con rigor por la élite de los ingenieros militares y de los políticos y hombres de guerra - polemólogos- de esa época, y ello mismo denuncia la existencia latente de una cuestión de estado, de un problema virtual que entonces emerge con preci- 
sión ante la conciencia del país, y que es el problema o la llamada "cuestión de Africa", que terminará siendo con el tiempo la "cuestión de Melilla" (Torres Campos, 1894).

No concozco ningún documento tan revelador de ese problema, y a la vez tan temprano en el tiempo, que el denominado como Dictamen del Señor Marqués de la Mina sobre conservar o abandonar los Presidios Menores, documento dirigido al marqués de Esquilache en el año de 1765.

El informe de De La Mina se encuentra situado al final de una larga trayectoria de consultas y de memoriales que habían terminado por sumir en el desconcierto al nuevo gobierno de Carlos III. El prestigio logrado por el marqués como teórico militar y como Capitán General de los Ejércitos hace que hasta él llegue la responsabilidad de decidir por fin el destino de las guarniciones españolas más extremas en la costa africana: los presidios de Melilla, el Peñón y Alhucemas.

Los últimos documentos sobre el estado de la cuestión que le son remitidos por la Secretaría de la Guerra al marqués de la Mina, pertenecen a ingenieros y militares de carrera como Cavallero, como Font, Bodopih y Justiniani, con un especial conocimiento de las condiciones de los territorios en cuestión. Todos estos informes, como nos hace saber De la Mina, eran en ese momento favorables a la demolición sin paliativos de los tres presidios, tal y como resume:

Los Oficiales citados con el fundamento experimental de haver estado en cada uno de los Presidios y sobre el mismo terreno con examen del todo y de sus partes dicen unánimes que no hallan razón Christiana, Política, ni Militar para conservarlos (De la Mina, 1923, pág. 5).

De la Mina, que confiesa (De la Mina, 1923, pág. 5) no haber podido dormir, desde que se le ha encargado la elevación del dictamen, rechaza en una primera instancia esta solución drástica, para retormar el problema enmarcándolo ahora en un contexto de necesidades reales, pero también políticas, y desde luego simbólicas, más amplio. Sopesando los motivos antiguos que determinaron la conquista de estas tierras, los encuentra diferentes y ajenos en buena medida a los motivos que en su 
tiempo se podían aducir en nombre de su conservación, que al decir de nuevo del marqués eran pocos, puesto que escribe:

He oído siempre la voz común de su gasto, de su inutilidad e inconvenientes por la deserción, el clamor y el disgusto de la tropa quando se acercan Regimientos a Málaga, y el riesgo de destacarlos en los Presidios, donde incurren en la infamia aborrecible de pasarse algunos a los Moros a buscar otra esclavitud por la ojeriza y el horror con que temen al Presidio, $y$ por fin el grito universal de ser unos puestos perjudiciales y peligrosos (De la Mina 1923, pág. 6).

Pese a este balance negativo realizado en primera instancia por el informante, la responsabilidad de un parecer que va a imponer -0 eso al menos cree su redactor - un giro a la historia misma, le hace dirigir nuevas consultas, esta vez a dos de los más ilustres ingenieros en que podría haber reparado: se trata por un lado, de Pedro Lucuce, quien luego sería director de la Real Academia de Matemáticas de Barcelona (Capel, 1989) y, de otro, de Pedro Cermeño, Teniente General conocido ya por sus intervenciones en los nuevos proyectos arquitectónicos de carácter defensivo realizados en Orán y en Ceuta. A ellos se añade también el informe de Antonio Gaver, que era entonces Ingeniero en Jefe y que estaba a la sazón también destacado en Orán, donde había llegado a ser Director de su Academia de Matemáticas.

La visión que estos tres ingenieros tienen acerca de las plazas en cuestión, va a ser decisiva en el sentido de orientar definitivamente el informe del marqués de La Mina, por cuanto estos tres ingenieros, desde el conocimiento que les suministran su detenida experiencia de las virtualidades militares, poliorcéticas de las plazas, sentencian en el sentido de abogar por la conservación del Peñón y de Alhucemas y, simultáneamente también, por la demolición de la plaza de Melilla, la cual, por aquellas fechas, no estaba dotada del puerto que más adelante reconvertiría su valor estratégico.

De nuevo la valoración de la verdad geopolítica del territorio se realiza sin falsas concesiones a la retórica de lo patriótico, y hasta podemos decir que hay un matiz de crítica, un decidido enfrentamiento a las posiciones idealistas y poco ancladas en las realidades políticas, que la conservación y tenencia de un territorio de ultramar implica. Así escriben que: 
En el día, de los tres Presidios, los del Peñón y Alhucemas son escollos aislados, distantes entresi, sin comunicación, ni por el aire que no se atreven a pasar a tierra aunque perezcan de hambre, $y$ sed, de cuyo peligro están siempre amenazados por las contingencias del mar; $y$ el tercero, Melilla, (es) un Yztmo sin puerto, ni utilidad, no se yo como pueden adaptarse a lo pasado, ni como se verificará que son el freno, y el terror de la berbería, Plazas Fronteras, y defensa de las nuestras... Encerradas las Guarniciones del Peñón, y Alhucemas en sus reducidos peñascos, y la de Melilla en sus fortificaciones porque no tiene objeto para salir de ellas y la experiencia ha enseñado que cuesta muchas desgracias sin utilidad, no son los Presidios escuela de la tropa, ni ai razón militar que lo disculpe (De la Mina, 1923, pág. 10).

De la Mina parte de nuevo de esta posición, que ya va a hacer suya, para repensar de nuevo la realidad compleja de estos territorios. En su dictamen hay una exploración por la historia de la conquista africana y del ideal primitivo que movió a los Reyes Católicos (García Figueras, 1947), hasta llegar a lo que era su presente, donde declara:

Mui remota sino imposible en la vista mas perspicaz, o el discurso que más prevea lo futuro, es la esperanza de volber a las antiguas conquistas, ni que convenga emplear la Sangre, y los Tesoros en hacerlas, porque jamás pudieramos internarnos, por ser un país donde sólo se posee lo que se pisa, porque son gente sin fe para el trato, y el comercio, y porque no representan objeto digno a la gloria, ni al interés por lo qual no se descubre razón de Estado que lo promueva, y todas las que se ha impuesto lo impugnan (De la Mina, 1923, pág. 11).

Esta referencia obsesiva y negativa en extremo para con la inmovilidad del cuerpo de ejército, contenido en los muros estrechos de la plaza, es una nota más añadida a las que aseguran la modernidad de la visión dromológica —es decir teoría del Estado como movimiento, como 
acción, como guerra (Virilio, 1984) -, que anima siempre toda visión de los problemas estatales tal y como se analizan desde la minoría ilustrada.

Hacía tan solo cincuenta años que un conocido general del ejército español en Italia, Teodoro Barbo, había enunciado y defendido técnicamente justamente lo contrario de lo señalado como gran defecto de los presidios por De la Mina. Barbo había ofrecido en memorial al rey Carlos III, lo que se pensaba fuera la solución para todos los problemas militares del ejército y la política española en Europa (y suponemos que pretendía que fuera también valedero para Africa): se trataba de construir, en principio en la porción de continente bajo dominio de la Corona, una serie de fortalezas inexpugnables donde los cuerpos del Ejército españoles pudieran ejercer aquello para lo que parecían entonces más capacitados, y que verdaderamente los ha hecho famosos en todas partes: la defensa a ultranza, la defensa numantina, todo aquello, en fin, que negarán más adelante los polemarcas modernos, de Vauban a Napoleón (R. De la Flor, 1989).

En sintonía con estos últimos, De la Mina explora la contradicción abierta que en todo uso de un ejército hay cuando éste sólo se concibe en un sentido de estatismo y de defensa. La imposibilidad de la movilidad, la negación o coerción del ejercicio de una fuerza y de una energía y rapidez de la violencia y la conquista, orienta estas páginas ilustradas del marqués y nos declaran con ello la extrema modernidad de sus planteamientos, al tiempo que nos informan en avance de la verdad histórica proyectiva que contienen sus especulaciones.

'Es en el terreno mismo de estas especulaciones, donde De la Mina nos ofrece también una serie de consideraciones acerca del estado de defensa de Melilla y los presidios de Alhucemas y el Peñón.

$Y$ aquí hay que señalar de nuevo las profundas mejoras introducidas por lo que fue el nuevo Reglamento de los presidios puesto en vigor en el año 1743. Reglamento que remodeló la presencia del personal humano; que regularizó también los contactos con la Península por mar y que introdujo por último efectivas medidas que mejoraron el abastecimiento siempre problemático y la percepción a su tiempo de los sueldos de los militares allí destacados. Todo lo cual lograba una tropa con una nueva moral, que el marqués reconoce como muy distinta ya a la de la larga decadencia que durante el siglo XVII tuvieron que soportar estos enclaves, abandona- 
dos en cierto modo por una política estatal poco solidaria para con los problemas de quienes eran sus servidores.

La mejora de los trazados poliorcéticos, y, en paralelo, la mejora también sustancial de las condiciones de vida del ejército allí destacado, obra, igual que en el caso de Orán, de una política ilustrada y progresista, no consigue hacer olvidar para el redactor de este informe cuál es el verdadero problema que en aquellos tiempos afligía este dominio territorial, totalmente desasistido también por entonces de una estrategía global geopolítica que pudiera enmarcar su presencia y defender su necesidad. En este punto, el informe es singularmente preciso, cuando De la Mina llega a escribir que:

No descubro por fin ventaja positiva en nada, sea Cristiana, Militar, ni Política, y muchas negativas y evidentes que influyen a la destrucción de los tres Presidios, pero con la desgracia inevitable de no poderse practicar en los dos, el Peñón $y$ Alhucemas que entiendo se deven conservar como un mal preciso, o como la llaga que no se cierra por rezelo de que aquel humor decline a parte más noble (De la Mina, 1923, pág. 12).

La salvaguarda bajo la Corona del Peñón y de Alhucemas, entiende De la Mina que es una medida política, sobre todo para tranquilizar a las poblaciones costeras peninsulares (Muy en especial las de la fachada levantina que vivían en una perpetua psicosis bélica, que las obliga a crear un propio sistema de fortificación (Vilar, 1979), para las cuales durante todo el Antiguo Régimen los presidios fueron una especie de escudo psicológico contra la pujanza de los turcos y argelinos, porque podría suceder, escribe de nuevo, que:

Los Pueblos de nuestra marinas fronteras ocupados los presidios por los Moros clamen con razón, o sin ella atribuyendo al abandono de los Presidios cualquier barco que nos tomen aunque sea cien leguas distante y asi por contestar su fantasía, y acallar su quexa, propongo que el Peñón, y las Alhuzemas se conserven (De la Mina, 1923, pág. 13). 
Lin corolario de medidas políticas y militares culmina el informe, entre ellas podemos reseñar la cuestión relativa al modo en que se deben realizar las demoliciones de las fortalezas de Melilla y el modo en cómo también debe procederse a una ordenada evacuación del territorio. pues existía ya desgraciadamente el precedente de las retiradas desorganizadas realizadas en Ceuta y en Orán en 1708. Escribe:

Melilla entiendo que se demuela, sin grande empeño en arruinar sus obras y que se retire la Artillería $y$ efectos empezando antes de dexar conocer la idea para sacar los Vezinos y de los almazenes lo que no se considere preciso para el tiempo de la operación, y que las obras que miran a la Campaña no se toquen y se guarnezcan con más cuidado entonzes, de modo que la Plaza por aquella parte quede cerrada y con algunos Cañones de hierro al momento de su abandono, porque sino se executa así, y se da la comisión a oficial vizarro, se puede temer la tragedia de que los Moros se introduzcan al mismo tiempo a embarazar la evacuación (De la Mina, 1923, pág. 15).

Tan triste abandono, tal deprimente resultado al que se ha llegado después de tantas consultas, no llega a su término sin concebir también, paralelamente, una serie de medidas potenciadoras de lo que resta. Señalaremos entre ellas, la constitución de una flota estable que uniera el Peñón, Alhucemas y Orán; flota formada por cuatro javeques y siete galeotas. De nuevo también en este informe aparece la mención a la necesidad sentida en cuanto a la formación de compañías de naturales - hemos visto que su nombre era "mogatazes"-, de las que se llega a afirmar que:

Respecto de que antes que aquellas Guarniciones lleguen a completarse de naturales, como en lo antiguo pasará tiempo, es preciso que continúe la recluta voluntaria, hasta que se consiga, y me parece que volviendo a socorrer, y a asistir aquellas gentes en el pie que se practicaba, hasta que se varió el año de 1743, será más breve y más fácil su reemplazo... (De la Mina, 1923, pág. 16). 
Por todo ello, el marqués de la Mina valora Melilla con criterios ilustrados, como un conocedor del nuevo arte de la guerra, que más depende del aseguramiento de las redes logísticas, de las vías de provisión, que de la propia consistencia de las defensas. El Mediterráneo es para la España de aquel entonces un trazado de rutas inseguras y desde la Península se mira con nostalgia los restos del fuerte dispositivo de defensa, más testimonial ahora cuanto más lejano del suelo patrio. De la Mina pasa revisión, insisto, con nostalgia perceptible a lo largo del informe, a lo que había sido el total de las posesiones españolas en el Norte de Africa, es decir: Melilla, Carsasa, Mazalquivir, el Peñón de Vélez, Orán, Tremezón, Tripli, Buxia, Isleta de Argel, Mostagan, Túnez y su Goleta, Bona, Caramany, Monasterio, Los Esfaques, Susa, La Mahometana, Larache, la Mamora, Alhuzemas, Orán y Ceuta, que había sido cedida por los portugueses en 1668 por el tratado de Lisboa. El conjunto de estas posesiones, como escribe el redactor, creaban un dispositivo entonces infalible y es que:

\section{Comunicándose entre sí cubrían nuestras costas} en ambos mares, aseguraban nuestra quietud y ponian en dominio y contribución mucha parte de las tierras firmes de la Berbería.

En el presente de desengaño en el que escribe el marqués, no le cabe otro remedio que valorar esos pequeños espacios militarizados resto de otras épocas en función de un vector puramente logístico, atado a una economía, y de modo particular a unas condiciones reales de la Marina de Guerra. Ello representa una concepción moderna, ilustrada, en comparación con la autocomplacencia que los ideólogos de la política española habían venido sosteniendo secularmente. Los ingenieros consultados que apuestan por la destrucción de Melilla, lo hacen partiendo de análisis centrados en la realidad exclusiva de sus fortificaciones, de su calidad y resistencia al asalto, mientras el marqués se esfuerza en su informe por trascedender todos los condicionamientos particulares, para llegar a una síntesis integradora con respecto a la verdad de la situación.

El mantenimiento proclamado de Alhucemas y el Peñón y el abandono paralelo de Melilla, adquiere así en este contexto el valor de un macroanálisis que trata también de mantener la ilusión en unos significados 
simbólicos y que, por lo tanto, cierra también el paso a un abandono absoluto que no dejaba de ser recomendado, como hemos visto, por los técnicos.

Realizado en 1765, este informe tan detallado no tuvo aceptación, en los términos en que estaban redactadas sus conclusiones, entre los ministros del entorno de Carlos III, que claramente no se decidieron a dar el paso que implicase el desmantelamiento de Melilla, tal y como hemos visto que era aconsejado. Por el contrario, Grimaldi, el conde de Aranda y, por lo que parece, el propio Carlos III, diseñaron un plan alternativo para la conservación en su integridad del territorio norteafricano, esta nueva forma de política de paz ilustrada pasaba por la firma con el Emperador de Marruecos, Mohamed Ben Abdalah, de lo que iba a ser el gran Pacto de Paz y Comercio de Marraquech, el 27 de mayo de 1767, firmado por parte de España por un plenipotenciario de excepción, el célebre marino Jorge Juan, autor de toda la renovación dieciochesca de nuestra marina de guerra (Rodriguez Gasado, 1946).

El Tratado aseguraba para España una posesión y una consolidación indiscutida ya de los presidios y plazas, que recordemos que eran por aquel entonces: Ceuta, Melilla, el Peñón, Alhucemas y Orán, y lo que es más interesante, su artículo 19 incluía la posibilidad difusa de un ensanche, en términos civiles, de estas plazas militares, con vistas a suprimir ese peligroso hinterland, ese vacío y tierra de nadie, ese glacis estéril para el comercio y el asentamiento civil, que, rodeando los establecimientos militares, tanto había contribuido a asfixiarlos:

Los ensanches que S. M. Católica pide en los cuatro Presidios los prohibe enteramente la Ley; desde el tiempo que se tomaron fijaron sus límites Sus Majestades Imperiales por dictamen de sus Taleb y Sabios, y juraron de no alterarlo, cuyo juramento han practicado y practican todos los Emperadores, $y$ es causa que su majestad Imperial no pueda concederlo, sin embargo que su Real ánimo quisiera extenderse mucho más. No obstante, para renovar dichos Limites y marcarlos con Pirámides de piedra, nombra por su parte al Alcalde Acher, Gobernador de Tetuán, y lo que éste acordare y marcare por Límites, de acuerdo con el Comisario que Su Majestad Católica nombrará, Su Majestad Imperial lo da por 
acordado y marcado, así como el Plenipotenciario de su Majestad Católica... (Cazenave, pág. 15).

La firma solemne de este Tratado no implicó, sin embargo, como venía siendo ya habitual, ningún tipo de estabilidad para la zona dominada por la Corona. Muy al contrario, ya desde el comienzo de los años 70 del siglo, los gobernadores militares de los presidios y los embajadores destacados de los reinos norteafricanos saben que el asalto a estas plazas es eminente.

\section{DF LA DEFENSA A ULYRANZA A LA PBRDIDA DE ORAN Y BL DESCABALAMIFITO DEL STSTEMA DE DEFEMGA}

El Estado español se apresta a defender entonces con lógica y coherencia los términos de los tratados firmados y desarrolla para ello muy tempranamente, y con una previsión sin precedentes, una labor de preparación para la guerra de las plazas, que va luego a fructificar en la defensa melillense durante la guerra de 1774-1775 mantenida con total éxito (Miranda, 1939).

Para esta defensa, que necesita de unos pilares teóricos y de un desarrollo práctico que acompase a aquellos, Grimaldi envía primero a una serie de comisiones técnicas que redactan sus informes sobre el estado de la plaza de Melilla, que entra entonces en un periodo de febril actividad y mejora de su recinto defensivo. La renovación del material artillero, la creación de las baterías alta y baja de la Concepción sobre la Ensenada de los Galápagos, son algunas de las mejoras reseñables en el quinquenio 70/75, y de alguna manera conforman todavía hoy, como reconoceremos todos, parte de lo que más estimable tiene hoy Melilla como fortaleza.

En todo caso, estas innovaciones contrastan poderosamente con el estado pésimo en que se encontraba la plaza tan sólo 60 años antes, en el momento en que fue sitiada por el Rey de Marruecos, en 1715 (Anónimo, 1909).

Lo que ha ocurrido entre tanto es el comienzo del empleo de la artillería por los árabes, cuya primera utilización se sitúa en 1721; empleo que fuerza ya, por parte española, a lo que es un rapidísimo desarrollo de las condiciones poliorcéticas de las plazas de soberanía. La llegada de Juan Serlock a Melilla por el año 1774 , cierra ese conjunto de medidas que hizo 
la plaza inexpugnable en el momento de declaración de la guerra, el 23 de octubre de 1774.

Realmente ese año es un momento crucial para Melilla, pues fue sólo la coherencia con que desde el gobierno ilustrado se afrontó la defensa de esta plaza la que hizo que no se perdiera para siempre el enclave. Ese esfuerzo marca, por otra parte, el punto más alto de nuestra política africana por aquellos años; política que desde ese momento tendría que encarar por largo tiempo una situación cada vez más inestable y deprimida. $Y$ es que los años 74 y 75 vieron, por un lado, el espectáculo de una defensa inteligente y organizada de un territorio, como fue el caso de Melilla, y presenciaron también el último intento expansionista que supuso la expedición a Argel y el terrible fracaso consecuente que cosechó O'Reilly (Martínez Campos, 1965; Fernán Núñez, 1944, pág. 119-184; El Kebir. 1979).

Respecto a Melilla, creo que nos queda entre los papeles de Bauer un documento muy interesante referido a esos años, se trata de un tipo de documento singular de entre los muchos que producía el ejército, un llamado Plan de Defensa del Presidio de Melilla (Bauer 1923, págs. 19-25). EI texto viene sin firma, pero fechado en 1774 , es evidente que fuc producido bajo el gobierno de Juan Serlock, y hasta quién sabe si se trata de un informe propiamente suyo.

El informe, demasiado técnico para extraer de él referencias que puedan interesar de un modo general, señala, sin embargo, un defecto poliorcético secular en la plaza de Melilla; defecto que ya se había puesto de relieve en el Sitio de Melilla por Mohamed Ben Abdel-Lah, en 1754; que había empleado por primera vez en campaña la artillería contra la plaza de Melilla. Se trata de la existencia de los llamados padrastros o alturas superiores en cota a la del propio sistema defensivo, cuestión palpable por ejemplo en la amenaza que la Puntilla supone para el Fuerte de la Victoria Grande. Otro inconveniente claro de la plaza estriba en su poca disponibilidad de mano de obra, para los incesantes trabajos de fortificación:

Todos estos proyectos - se lee en el Plan-serían mui ventajosos si hubiese lugar y arbitrio para su execución, pero hay un cúmulo de tropiezos que lo imposibilitan, lo primero la falta de materiales para su efecto, el número de tropas para sostener aquellos trabajos $y$ de Peones $y$ operarios por 
ser mui limitado el actual de todos estos individuos que en el dia guarnecen esta Plaza y aunque los auxilios pedidos vengan con oportunidad no se hará poco en atender, a costa de inmensa fatiga a las más exenciales, y menos expuestas que siguen (M. Bauer, 1923, pág. 20).

El informe pone un especial énfasis en lo que podríamos llamar guerra subterránea (Sanz, 1776), con la construcción de numerosas minas, galerías y pozos de escucha tanto para el traslado de hombres a los puntos en conflicto como para la detección del enemigo y voladura de sus posiciones. Esta necesidad sentida de reconstruir o construir de nuevo todo un tejido subterráneo, pertenece a un eje de preocupaciones modernas en el trazado defensivo de las plazas, y por aquellos mismos años, vemos cómo también en Orán el ingeniero director Martín Cermeño horada todo el subsuelo de la plaza con gigantescos túneles, minas y almacenes a prueba de bomba, concibiéndo estas estructuras a modo de distribuidor de un flujo guerrero que está a cubierto de toda observación y que puede llegar sorpresívamente a todo lugar (Barneaud, 1922). Y es por aquellos mismos años también cuando surge lo que es el primer tratado teórico en nuestro país, acerca de las virtualidades de ese tipo de intervención: los Principios militares en que se explican las operaciones de la guerra subterránea, de Raymundo Sanz, publicado en 1776.

Ignoro, en el caso de Melilla, lo que hoy, al presente, resta de toda esta articulación de una defensa en el subsuelo, pero desde aquí debo decir, por lo que a la conservación del patrimonio se refiere, que toda la infraestructura bajo el subsuelo de una fortificación es parte vital de su concepto y debería ser puntualmente respetada, explorada también, y puesta en valor, y no destruida y cegada como en muchas partes se puede comprobar que se viene haciendo.

La puesta en defensa de la plaza de Melilla en el punto en que la hemos relacionado, evitó un desastre inminente por aquel entonces, que, sin embargo, no tardaría en producirse unos años después en el caso de la plaza que era el orgullo poliorcético de la Corona española en el Norte de Africa. La pérdida de Orán, un tanto inexplicable, en todo caso precipitada y no suficientemente amparada proporcionalmente en la amenaza militar 
que sufría, adquirió entonces el valor de un síntoma. Se cerraba entonces, en 1791, el amplio círculo proyectado por la reforma ilustrada.

Muchas empresas y la marcha general de la reforma militar y política quedaban entonces estancadas, surgiendo nuevas zonas en conflicto a las que se hizo imposible acudir para su auxilio.

Si en 1774 la previsión de la Secretaría de Guerra en Madrid había desencadenando toda una serie de medidas que fueron efectivas en el caso de Melilla, vemos como tan sólo quince años despúes Orán es reconquistada por Argel, cogiendo por completo de improviso al ejército allí estacionado. Ejército desmoralizado, que ya no se entrega a ninguna suerte de defensa, pese a encontrarse en la ciudad mejor defendida de toda la costa sur mediterránea.

Este abandono emblemático cierra el siglo, cierra una cierta época de reconstrucción y balance que se vivió en España con los monarcas ilustrados y proyecta su sombra sobre un futuro inmediato, pleno de incertidumbres. El modelo que el estado ilustrado pretendió realizar con plena conciencia de sus limitaciones en el Norte de Africa, no fue alcanzado, ni siquiera se pudo conservar en lo que era su pieza clave -Orán-, y ello justifica una visión del problema, aquí sólo abordado en sus términos más generales, en clave de crisis.

Antes de que esta crisis se produjera, junto o provocada por una parálisis generalizada de los mecanismos del Estado, se produjo, como hemos visto, un intento de replanteamiento del problema de Africa en unos términos más realistas; replanteamiento ilustrado que termina siendo desbordado por los acontecimientos que generalizan lo que es una crisis y retracción casi total de aquel sistema de defensa que había sido largamente construido desde los tiempos inaugurales de los Reyes Católicos. 
ANONIMO, Relación del sitio de la villa de Melilla sitiada por el exército del Rey de Marruecos en 1715, Madrid, Hijos de R, Alvarez, 1909.

ANONIMO, Reglamento, Ordenanza e Instrucción de S. M. para la subsistencia, régimen y enseñanza de la Real Escuela o Academia Militar de Mathemáticas, establecida en barna y las pariculares en Orán y Ceuta, unas y otras al cargo, y dirección del Cuerpo de Ingenieros para la enseñanza de los Oficiales, $y$ Cadetes del Exército. Barcelona, Francisco Suria y Burgada, 1775.

ARQUES, E.: Las adelantadas de España, Madrid, CSIC, 1966.

BARNEAUD, E.: "Galeries souterraines d'Oran", Afrique du Nord Illustrée, 1922.

BAUER, I.: Manuscritos (varios sobre Africa), Madrid, ed. Ibero Africana, 1923.

CAPEL, H. et alt.: De Palas a Minerva. La formación cientifica y la estructura institucional de los ingenieros militares en el siglo XVIII. Madrid, Serbal, 1989.

CARCEDO, G.: El Riff, memoria o ligeros apuntes que pueden servir de introducción al estudio del pensamiento de España en Africa, Madrid, Piferrer, 1839.

CAZENAVE: Presidios españoles en Africa. Siglo XVIII.

DECHAUD, R.: Melilla et les présides, París, Sociéte de Géographie Commerciale, 1908.

EL-KEBIR, A.: Siete legajos del Archivo general de Simancas sobre la expedición de Argel de 1775, Orán, Dea, 1979.

EL-KORSO y EPALZA, M.: Orán et l'ouest algérien au XVIII siècle d'après le rapport Arámburu, Argel, Liniversité, 1978.

EPALZA, M.: "Note sur les forteresses hispaniques au Maghreb", Revue d'Histoire Magherbine, 13-14 (1979).

EPALZA, M. y VILAR, J.B.: Planos y mapas Hispánicos de Argelia, siglos XV-XVIII. Madrid, Instituto Hispanoa-Arabe de Cultura, 1988.

Ingenieria militar y sistema defensivo en Orán y su región bajo la dominación española (siglos XVI-XVIII), Congreso Cartagena y el Mar, Murcia, Diputación, 1984.
FERNAN NUÑEZ, Cionde de: Compendio histórico de la vida de Carlos III, Madrid, 1944.

GARCIA FIGUERAS, T.: La ocupación de Melilla en el pensamiento político de los Reyes Católicos s.I., s.i., s.a. Melilla, Gráficas El Quijote, 194?.

Marruecos. La acción de España en el Norte de Africa.

GOMEZ DE ARTECHE, J.: "El Marqués de Verboom, ingeniero militar flamenco al servicio de España", Bol. de la Real Academia de la Historia, 34 (1899), págs. 343-350.

GUZMAN Y DAVALOS, Pedro José Guzmán (Marqués de la Mina): Dictamen del Señor Marqués de la Mina sobre conservar o abandonar los Presidios Menores (1765). En I. Bauer, Manuscritos varios sobre Africa, Madrid, Ed. lbero-africano-americana, 1923.

MARTINEZ CAMPOS, C.: España bélica. Siglo XVIII. Madrid, Aguilar, 1965.

MAILLLO, F.: De la presencia española en el Norte de Africa durante la modernidad., en Congreso de las Tres Culturas, Medina del Campo, 1991. En prensa.

MERINO, Mªl Mar: ${ }^{\mathrm{a}} \mathrm{La}$ colonización de Sierra Morena y Nueva Andalucía. El sueño logrado", M.O.P.U., 356 (1988), págs. 92-110.

MIRANDA, F.: El sitio de Melilla de 1774 a 1775. Diario de ataque $y$ defensa de la plaza, Tánger, Instituto General Franco, 1939.

FLOR, R. de la: El fuerte de La Concepción y la arquitectura militar de los siglos XVII XVIII, Salamanca, Diputación, 1987.

(Ed.) Tratado de arquitectura militar de Mateo Calabro (1732), Salamanca, Universidad, 1991.

FLOR, R. de la: “Una utopía regresiva de la arquitectura militar en la España de Carlos II", en P'edro Navascués y José Luis Gutiérrez, Medievalismo y neomedievalismo en la arquilectura española, Salamanca, Universidad, 1989., págs. 131-145.

REZETTE, R.: Les enclaves espagnols au Maroc, París, Nouvelles Editions Latines, 1976.

RODRIGlez CaSADO, V.: Política monárquica de Carlos III, Madrid, C.S.I.C., 1946. 
SANZ, R.: Principios militares en que se explican las operaciones de la guerra subterránea, Barcelona, Imprenta Eulalia Piferrer, 1776.

SLAREZ INGLAN, J.: El Teniente General Don Pedro Lucuce. Sus obras e influencia que ejerció en la institución militar en España, Madrid, Imprenta del memorial de Ingenieros, 1903.

TORRES CAMPOS, R.: “La cuestión de Melilla", en Revista General de Geografia Comercial, 125-128 (1894) págs. 39-53.

VALLEJO, J.: Memoria sobre el estado y valor de las plazas de Orán y Mazalquivir, ed. francesa de J. Cazenave, en Revue Africaine d'Alger 1925, págs. 323-368.

Relación de todas las obras de fortificación ycorrespondientes a ella, que se han executado en las plazas de Orán, Mazarquivir, y sus castillos..., 1738.

VILAR, J. B.: "Fortificación y defensa del litoral en el sur valenciano (siglo XVI-XVIII), Cuadernos de la Biblioteca Española de Tetuán, 19-20 (1979), págs. 131-164.

VIRILIO, P.: L' horizon négativ, París, Galilée, 1984. 
